\title{
Preparation of Bismuth Oxide Photocatalyst and Its Application in White-light LEDs
}

\author{
Yen-Chang Chu, ${ }^{1}$ Gang-Juan Lee, ${ }^{2}$ Chin-Yi Chen, ${ }^{3}$ Shih-Hsin Ma, ${ }^{4}$ Jerry J. Wu, ${ }^{2}$ \\ Tzyy-Leng Horng, ${ }^{5}$ Kun-Huang Chen, ${ }^{6}$ and Jing-Heng Chen ${ }^{4}$ \\ ${ }^{1}$ Ph.D. Program of Electrical and Communications Engineering, Feng Chia University, No. 100, \\ Wen Hwa Road, Taichung 40724, Taiwan \\ ${ }^{2}$ Department of Environmental Engineering and Science, Feng Chia University, No. 100, Wen Hwa Road, Taichung 40724, Taiwan \\ ${ }^{3}$ Department of Materials Science and Engineering, Feng Chia University, No. 100, Wen Hwa Road, Taichung 40724, Taiwan \\ ${ }^{4}$ Department of Photonics, Feng Chia University, No. 100, Wen Hwa Road, Taichung 40724, Taiwan \\ ${ }^{5}$ Department of Applied Mathematics, Feng Chia University, No. 100, Wen Hwa Road, Taichung 40724, Taiwan \\ ${ }^{6}$ Department of Electrical Engineering, Feng Chia University, No. 100, Wen Hwa Road, Taichung 40724, Taiwan
}

Correspondence should be addressed to Jing-Heng Chen; jhchen@fcu.edu.tw

Received 10 July 2013; Accepted 14 September 2013

Academic Editor: Jiaguo Yu

Copyright (C) 2013 Yen-Chang Chu et al. This is an open access article distributed under the Creative Commons Attribution License, which permits unrestricted use, distribution, and reproduction in any medium, provided the original work is properly cited.

\begin{abstract}
Bismuth oxide photocatalysts were synthesized and coated on the front surface of phosphor-converted white light-emitting diodes to produce a safe and environmentally benign lighting source. Bismuth oxide photocatalyst powders were synthesized with a spray pyrolysis method at $500^{\circ} \mathrm{C}, 600^{\circ} \mathrm{C}, 700^{\circ} \mathrm{C}$, and $800^{\circ} \mathrm{C}$. Using the absorption spectrum in the blue and UV regions of the bismuth oxide photocatalysts, the blue light and UV leakage problems of phosphor-converted white LEDs can be significantly reduced. The experimental results showed that bismuth oxide photocatalyst synthesized at $700^{\circ} \mathrm{C}$ exhibited the most superior spectrum inhibiting ability. The suppressed ratio reached 52.33\% in the blue and UV regions from 360 to $420 \mathrm{~nm}$. Related colorimetric parameters and the photocatalyst decomposition ability of fabricated white-light LEDs were tested. The CIE chromaticity coordinates $(x, y)$ were $(0.349,0.393)$, and the correlated color temperature was $4991 \mathrm{~K}$. In addition, the coating layer of photocatalyst can act as an air purifier and diffuser to reduce glare. A value of $66.2 \pm 0.60 \mathrm{ppmv}$ of molecular formaldehyde gas can be decomposed in $120 \mathrm{mins}$.
\end{abstract}

\section{Introduction}

White light-emitting diodes (LEDs) are a promising new lighting source. Compared with traditional lighting sources, white-light LEDs offer the advantages of low energy consumption, are free of mercury pollution, and are small, lightweight, durable, and reliable. Presently, the luminous efficiency of white-light LEDs exceeds that of incandescent light bulbs (approximately $20 \mathrm{~lm} / \mathrm{w}$ ) and that of fluorescent lamps $(60$ to $100 \mathrm{~lm} / \mathrm{w})$ [1]. Consequently, the applications of white-light LEDs will gradually transform from localized and accent lighting to indirect lighting and to main lighting, in the near future.

Two main methods have been developed to produce white-light LEDs, including multicolored and phosphorbased white-light LEDs. The multicolored white-light LED, based on a physical additive color-mixing principle, uses LED chips with the 3 primary colors (red, green, and blue; RGB) to obtain white light. The phosphor-based white-light LEDs use blue- or UV-light LED chips to excite yellow or RGB phosphors to generate white light. For LEDs to be an ideal, practical lighting source, several issues require consideration. A large amount of research is focused on the improvement of luminous efficiency, light extraction efficiency, color temperature, and color rendering index of white-light LEDs [25]. However, most commercial phosphor-based white-light LEDs produce blue light, UV leakage, and glare problems, which can be harmful to the skin, eyes, or other bodily organs [6]. Only a few studies have investigated these issues [7-9]. A healthy, safe, and environmentally friendly lighting source is in high demand. 


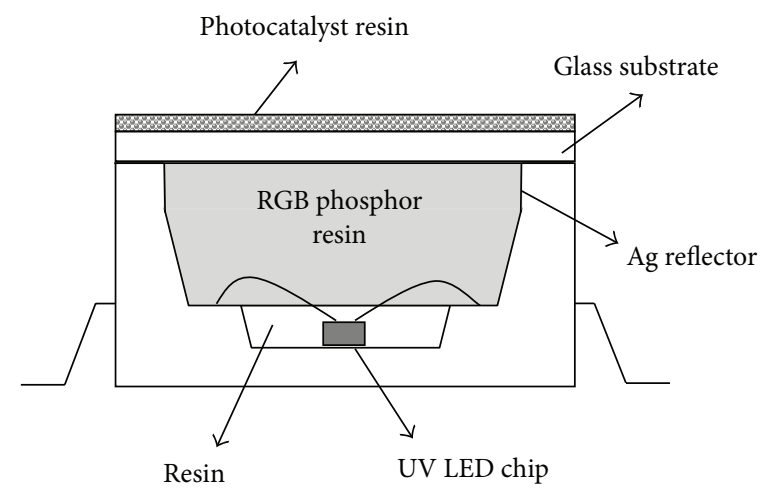

FIGURE 1: Schematic representation of the proposed white light LED coated with a layer of photocatalyst.

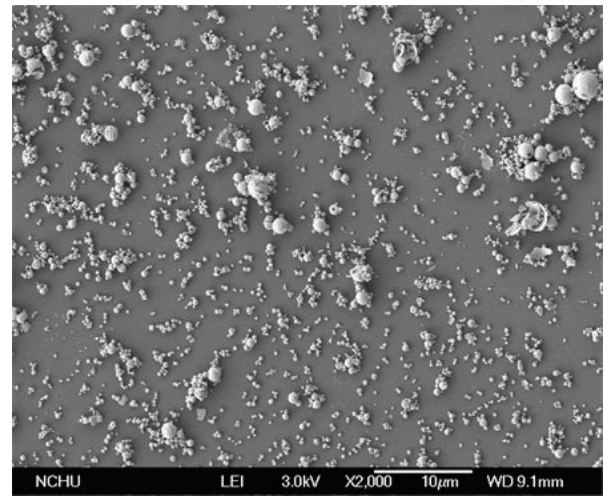

(a)

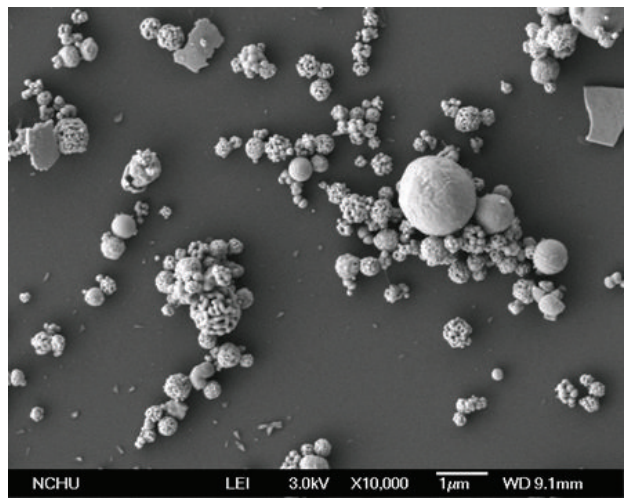

(b)

FIGURE 2: Bismuth oxide photocatalyst coating sample under FE-SEM at a magnification of $(a) \times 2,000$ and $(b) \times 10,000$.

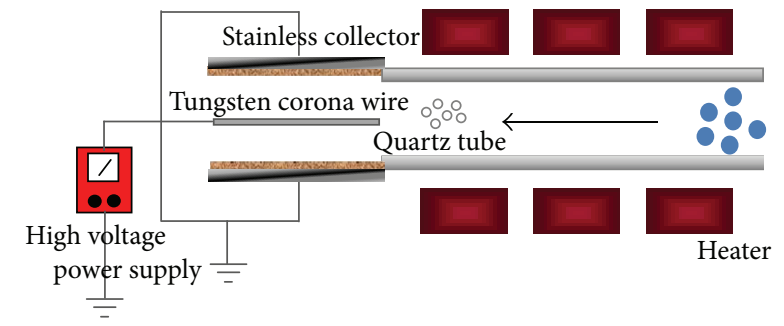

FIGURE 3: Schematic representation of spray pyrolysis method and static electricity deposition.

Photocatalyst materials have wide applications and exhibit the benefits of high activity, nontoxicity, low cost, and superior chemical and physical properties. Currently, most products which use photocatalysts use titanium oxide $\left(\mathrm{TiO}_{2}\right)$, which may be limited by application patents, and the activating wavelength is below $388 \mathrm{~nm}$. Therefore, as a photocatalyst, titanium oxide is not an optimal candidate for solving the blue light and UV-leakage problems of commercial phosphor-based white-light LEDs. By comparison, bismuth oxide $\left(\mathrm{Bi}_{2} \mathrm{O}_{3}\right)$ has an activating wavelength above $388 \mathrm{~nm}$. The energy band gap $\left(E_{g}\right)$ of $\mathrm{Bi}_{2} \mathrm{O}_{3}$ is 2.6 to
$2.8 \mathrm{eV}$, which has a broader absorption range in visible light. Accordingly, as a photocatalyst material, bismuth oxide is a suitable candidate for the suppression of blue light and UV in white-light LEDs.

Synthesis methods of bismuth oxide include spray pyrolysis [10], electrospinning [11], hydrothermal synthesis [12], co-precipitation [13] and sol-gel [14]. The spray pyrolysis method is a continuous fabrication procedure for ceramic powder. Powder with high purity and uniformity of particles is mass produced with this method. The electrospinning method produces nanofibers that have a superior activity and recycling rate than traditional nanoparticles. Although nanofibers have a lower energy band gap, the electron-hole pair has a higher recombination probability. The hydrothermal method is used to manufacture high crystalline powders and does not require calcine. However, the cost of production is high. The coprecipitation method uses atmospheric pressure to produce nanopowders, which have the advantages of being low cost, easy-to-use, and tiny particles of high purity. However, their crystalline structure is inferior. The sol-gel method produces powders which have the benefits of uniform holes, low sintering temperature, and narrow pore distribution, but organics contained in the product are difficult to remove during processing. Therefore, in this study, 


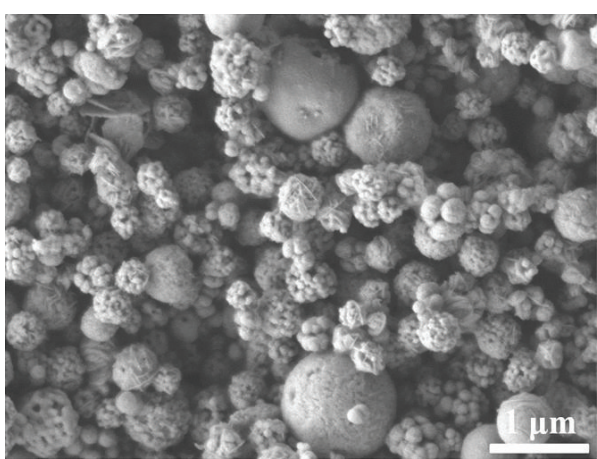

(a)

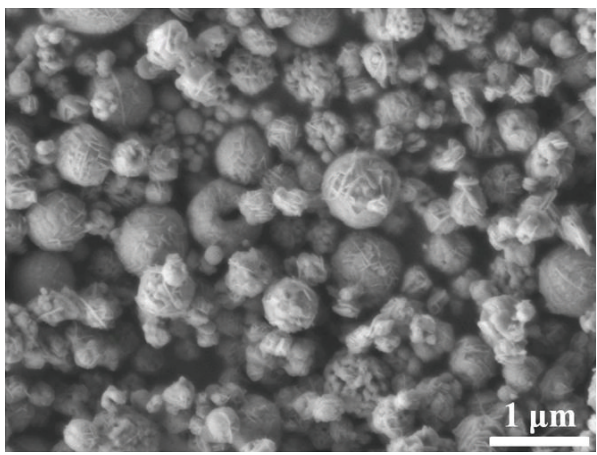

(c)

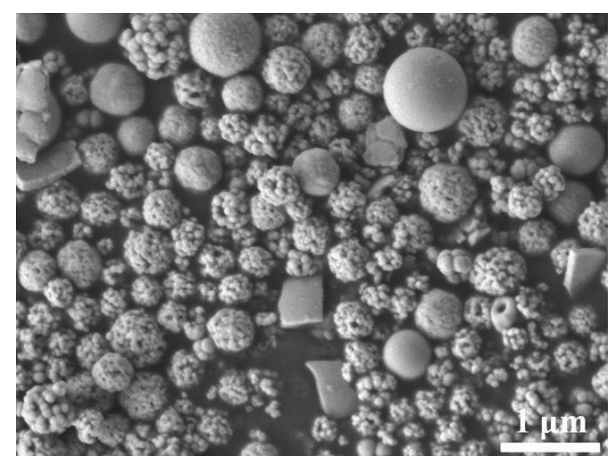

(b)

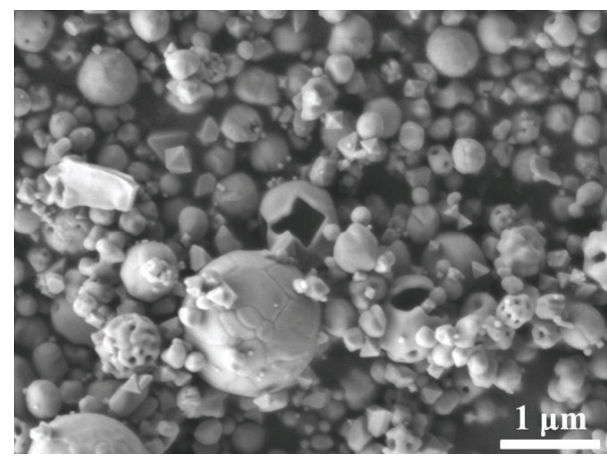

(d)

Figure 4: FE-SEM micrograph of (a) SP500, (b) SP600, (c) SP700, and (d) SP800 $\mathrm{Bi}_{2} \mathrm{O}_{3}$ powders.

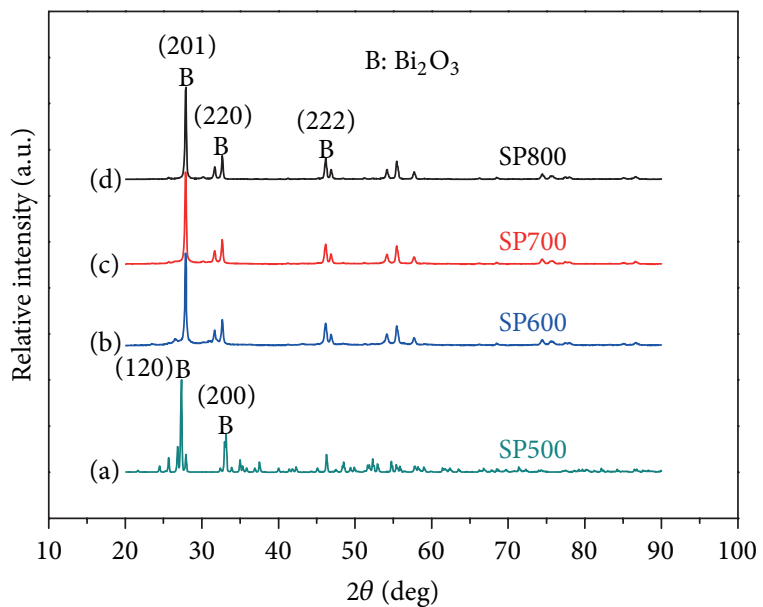

FIGURE 5: XRD patterns of (a) SP500, (b) SP600, (c) SP700, and (d) $\mathrm{SP} 800 \mathrm{Bi}_{2} \mathrm{O}_{3}$ powders.

the spray pyrolysis method was applied to synthesize $\mathrm{Bi}_{2} \mathrm{O}_{3}$ powder. Bismuth oxide photocatalysts were synthesized with a spray pyrolysis method at $500^{\circ} \mathrm{C}, 600^{\circ} \mathrm{C}, 700^{\circ} \mathrm{C}$, and $800^{\circ} \mathrm{C}$. The absorption spectrum in the blue and UV regions of the $\mathrm{Bi}_{2} \mathrm{O}_{3}$ photocatalyst was applied to phosphor-converted white LEDs to moderate the blue light and UV leakage problems. To show the feasibility of the concept, an RGB phosphor-converted white light-emitting diode, coated with a layer of photocatalyst on the surface of the LED package, was proposed. The related colorimetric parameters and photocatalyst decomposition of fabricated white-light LEDs were tested. It was concluded that the bismuth oxide photocatalyst material can be applied effectively to implement a safe and environmentally friendly white LED light source.

\section{Fabrication of White Light LED Covered with a Layer of Photocatalyst}

Figure 1 is the schematic representation of the proposed RGB phosphor-converted white-light LED, coated with a layer of $\mathrm{Bi}_{2} \mathrm{O}_{3}$ photocatalyst resin. Because the absorption spectrum of the bismuth oxide photocatalyst includes blue and UV regions, the blue light and UV leakage problems of phosphor-converted white LEDs can be significantly reduced. In addition, the coating layer of the photocatalyst can act as an air purifier and diffuser and reduce glare.

2.1. White-Light LED Packaging. A UV LED chip (HU1165W, TEKCORE) with a spectrum of 380 to $385 \mathrm{~nm}$ mounted on an SMD LED lead frame was used as the light source for exciting RGB phosphors. Inside the LED lead frame, the bottom layer and superstratum were filled with epoxy resin and RGB phosphor resin, respectively. The RGB phosphor resin was prepared by mixing red phosphor (RU-R6006S, NANTEX), green phosphor (RU-G503, NANTEX), blue phosphor (RUB403, NANTEX), and epoxy resin with a weight ratio of $1: 1.84: 7.83: 104$ and was baked in vacuum oven at $80^{\circ} \mathrm{C}$ for 3 hrs. A glass substrate coated with a layer of photocatalyst 


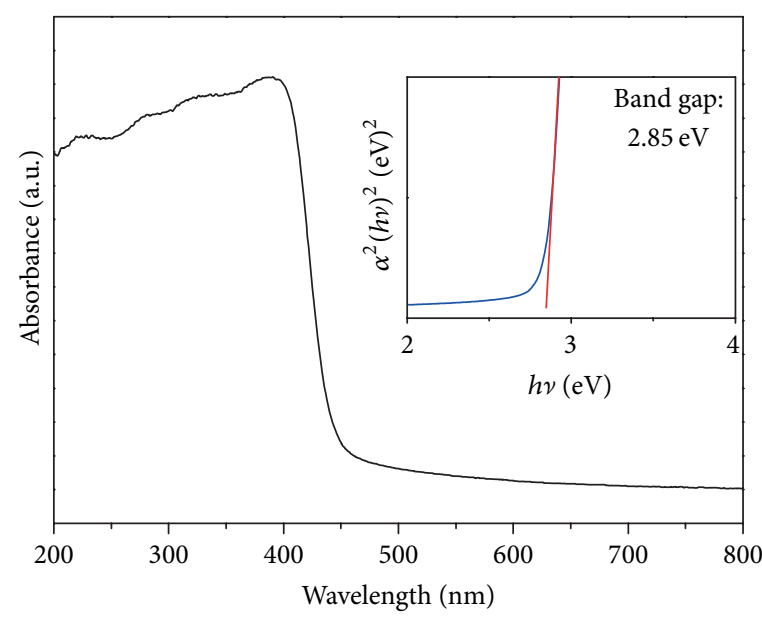

- SP500

(a)

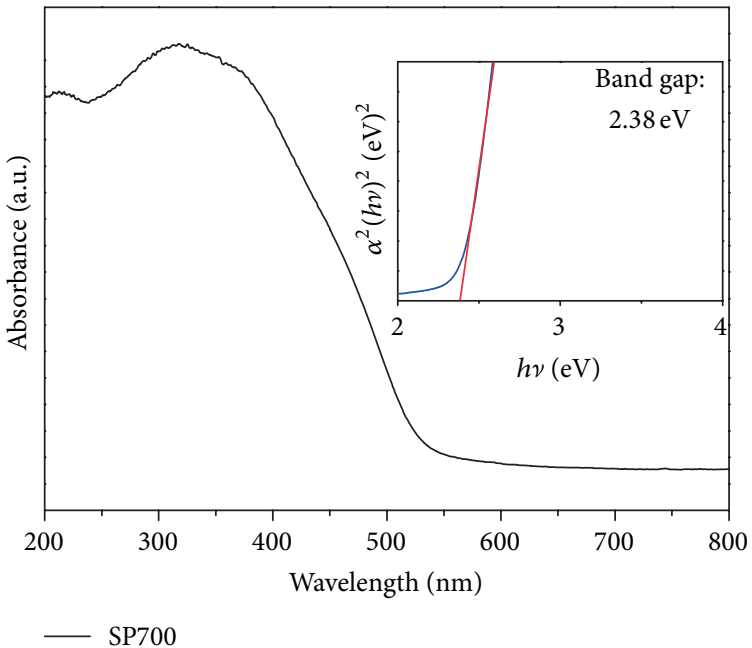

(c)

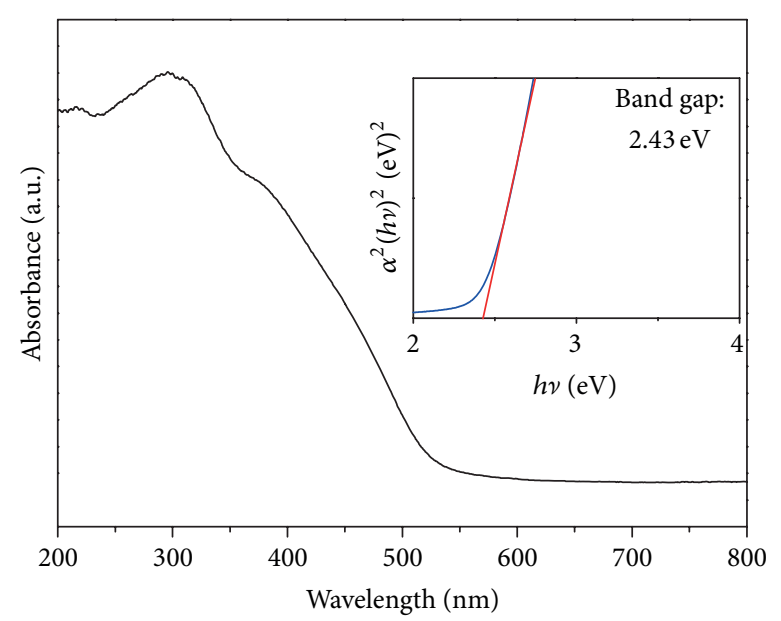

- SP600

(b)

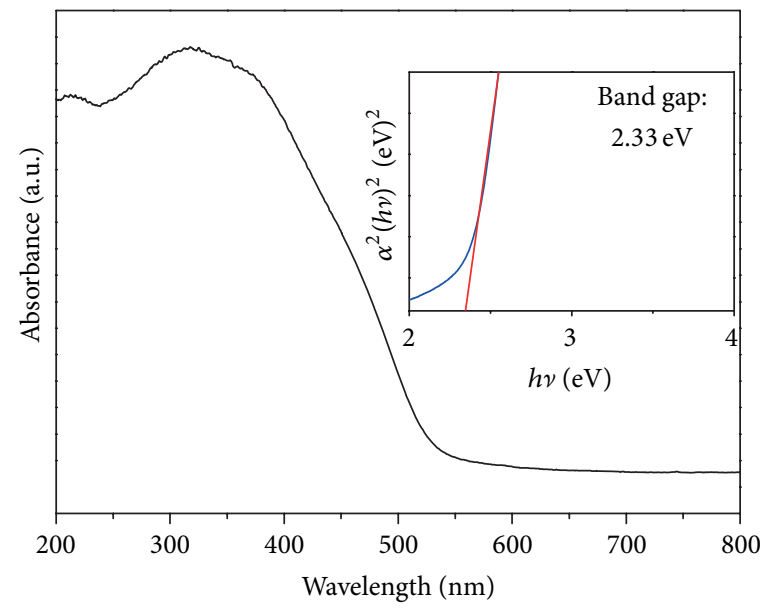

(d)

Figure 6: The light absorption of (a) SP500, (b) SP600, (c) SP700, and (d) SP800 $\mathrm{Bi}_{2} \mathrm{O}_{3}$ powders as a function of light wavelength.

resin covered the top of the LED package. By mixing the $\mathrm{Bi}_{2} \mathrm{O}_{3}$ photocatalyst and an adhesive in a weight ratio of $1: 15$, the photocatalyst coating was prepared using the screen printing method and then baked at $300^{\circ} \mathrm{C}$. The adhesive consisted of terpineol and ethyl cellulose ethoce with a weight ratio of $94: 6$. Figures 2(a) and 2(b) show the photocatalyst coating sample under scanning electron microscopy at a magnification of $\times 2,000$ and $\times 10,000$, respectively. From Figure 2, it can be seen that the quality of uniformity and adhesion are favorable.

2.2. Bismuth Oxide Photocatalyst Synthesis. The bismuth oxide $\left(\mathrm{Bi}_{2} \mathrm{O}_{3}\right)$ photocatalyst was synthesized with the spray pyrolysis method. Figure 3 shows the schematic representation of the spray pyrolysis method and static electricity deposition for the photocatalyst synthesis.

In the synthesis process, a precursor of $1 \mathrm{wt} \%$ bismuth nitrate peroxide solution was prepared by adding $10 \mathrm{~g}$ bismuth nitrate pentahydrate (BiNH) to $100 \mathrm{~mL}$ acetic acid, and diluting with $890 \mathrm{~mL}$ deionized (DI) water after the $\mathrm{BiNH}$ had dissolved completely. The precursor was nebulized as small droplets with a commercial nebulizer (King Ultrasonics Co., Ltd) at $1.65 \mathrm{MHz}$. The nebulized droplets were guided into a quartz tube with 3 heating regions, with gas flow and velocity of $27 \mathrm{~L} / \mathrm{min}$ and $27 \mathrm{~cm} / \mathrm{sec}$ and applying a voltage of $16 \mathrm{kV}$. The temperatures of the first and third regions were set to $200^{\circ} \mathrm{C}$ and $350^{\circ} \mathrm{C}$, respectively. The pyrolysis temperature in the second region was set at $500^{\circ} \mathrm{C}, 600^{\circ} \mathrm{C}, 700^{\circ} \mathrm{C}$, and $800^{\circ} \mathrm{C}$, and the resulting powders were thus denoted as SP500, SP600, SP700, and SP800, respectively. After drying for $24 \mathrm{hrs}$, the photocatalyst powders were scraped away from the stainless collector. The 4 powders were analyzed by field-emission scanning electron microscope (FE-SEM, JSM-6700F, JEOL), X-ray diffraction (XRD, D/MAX2500, Rigaku), and UV-Visible spectrometer (U3900, Hitachi). Figure 4 shows the FE-SEM microscopy of the SP500, SP600, SP700, and SP800 $\mathrm{Bi}_{2} \mathrm{O}_{3}$ photocatalyst powders, demonstrating that the pyrolyzed powders exhibited 


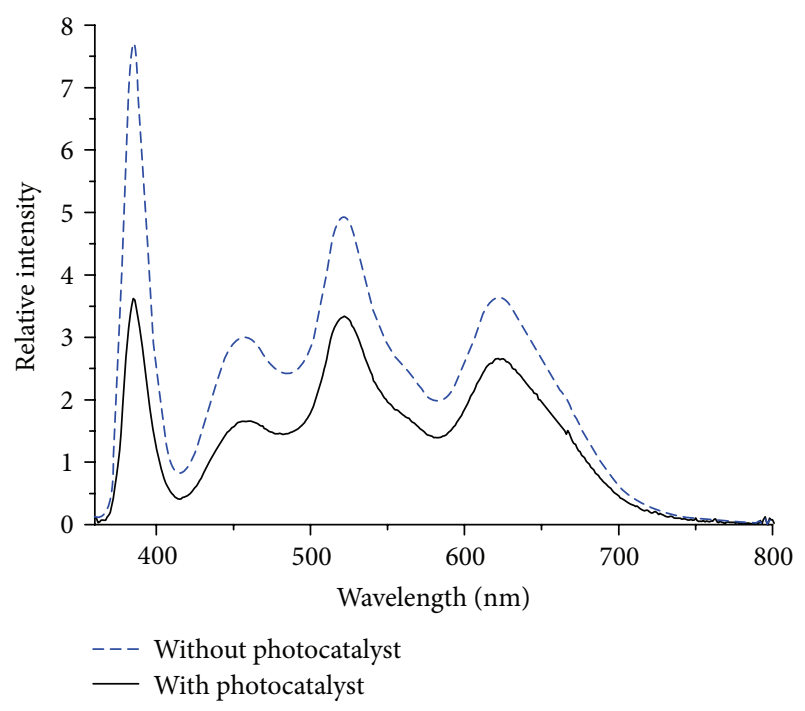

FIGURE 7: Spectrum comparison of the LED light source with and without covering a layer of photocatalyst.

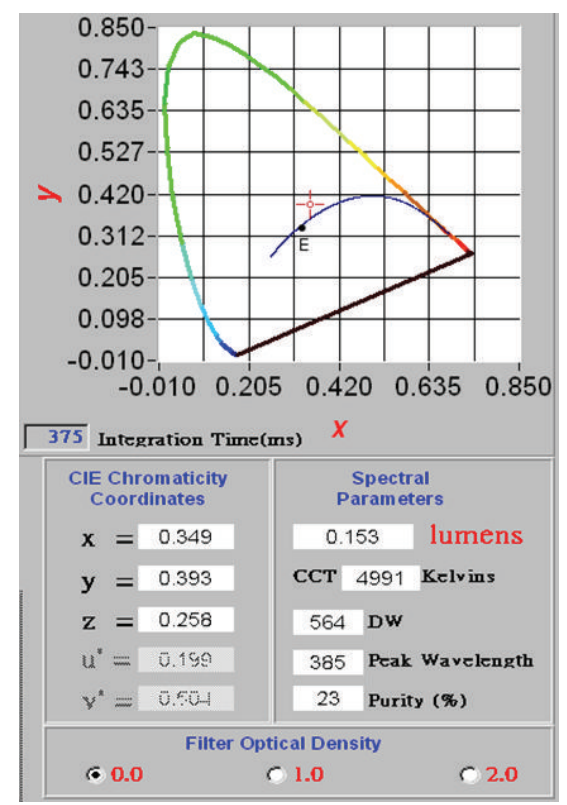

FIGURE 8: The colorimetric parameters of white LED coated with a layer of SP700 bismuth oxide photocatalyst.

spherical particulate morphology. Figure 5 shows the XRD patterns for the samples at 4 temperatures of the pyrolyzed powders. The results show that the diffraction peaks became sharper with increasing pyrolysis temperature, revealing the increases in crystallinity of the $\mathrm{Bi}_{2} \mathrm{O}_{3}$ powder. The mean grain sizes of SP500, SP600, SP700, and SP800 powders calculated by Scherrer's formula are $77.04 \mathrm{~nm}, 61.25 \mathrm{~nm}$, $64.19 \mathrm{~nm}$, and $67.94 \mathrm{~nm}$, respectively. The light absorption of the $\mathrm{Bi}_{2} \mathrm{O}_{3}$ photocatalyst powders can be determined by the reflection spectra. Figure 6 shows the light absorption of $\mathrm{Bi}_{2} \mathrm{O}_{3}$ photocatalyst powders as a function of light wavelength. The insets show the $(\alpha h \nu)^{2}$ plots as a function of the photon energy for the corresponding temperatures of pyrolyzed powders, where $\alpha$ is the absorption coefficient, and a function of light frequency. The energy band gaps $\left(E_{g}\right)$ for corresponding temperatures of pyrolyzed powders were $2.85,2.43,2.38$, and $2.33 \mathrm{eV}$. These values show a decreasing trend with the increasing of pyrolysis temperature. As shown in Figure 4, the particle size increases with the pyrolysis temperature. Therefore, the trend could be explained by the particle-size effect $[15,16]$. In addition, it is obvious that the range of the absorption wavelength extends to the blue and green spectrum region ( 436 to $533 \mathrm{~nm}$ ) with the increase in the pyrolysis temperature of the $\mathrm{Bi}_{2} \mathrm{O}_{3}$ powders.

\section{Colorimetric Parameters and Photocatalyst Decomposition Tests}

The fabricated white-light LEDs were driven (SourceMeter 2400 , KEITHLEY) at forward voltage and current of $3.48 \mathrm{~V}$ and $20 \mathrm{~mA}$ and were tested by the LED characterization system (LCS-100, SphereOptics). The relative intensities and inhibition abilities in various spectrum regions are shown in Table 1. From Table 1, it is apparent that the UV inhibition of $\mathrm{Bi}_{2} \mathrm{O}_{3}$ powder increases with the increase of pyrolysis temperature. However, the inhibition ability of the SP800 in the blue and UV regions degrades, because of the increase of grain size of the spray pyrolysis particles and the disappearance of the surface integrity of the spray pyrolysis particles, as shown in Figure 4(d). The specific surface areas of the SP700 and SP800 were $4.465 \mathrm{~m}^{2} / \mathrm{g}$ and $2.228 \mathrm{~m}^{2} / \mathrm{g}$, respectively. The degradation of inhibition ability in the blue and UV regions was a result of the dramatic decrease in specific surface area. Meanwhile, the specific surface areas of the SP500 and SP600 were $1.987 \mathrm{~m}^{2} / \mathrm{g}$ and $5.428 \mathrm{~m}^{2} / \mathrm{g}$, respectively. Though the SP600 owns a higher specific surface area than the SP700, the crystallinity of SP 600 is poor. Therefore, the SP700 exhibited the most superior inhibition ability in the short wavelength regions. A spectrum comparison of the LED light source with and without a covering layer of the SP700 photocatalyst is shown in Figure 7. The UV-suppressed ratio reached $52.33 \%$ in the region from 360 to $420 \mathrm{~nm}$; the visible light-suppressed ratio was $33.11 \%$ in the region from 420 to $780 \mathrm{~nm}$. In addition, colorimetric parameters of the whitelight LED were tested with CIE chromaticity coordinates $(x, y)$ of $(0.349,0.393)$ and correlated color temperature of $4991 \mathrm{~K}$ with a dominant wavelength of $564 \mathrm{~nm}$. The color purity was $23 \%$, and the color rendering index was up to 90, as shown in Figure 8. Figures 9(a) and 9(b) are the glare comparisons of the LED light source with and without a covering layer of the SP700 photocatalyst resin. Because of the particle scattering phenomenon, the coating layer of the photocatalyst can act as a diffuser, as shown in Figures 2(a) and 2(b). The glare problem was thus reduced.

The $\mathrm{Bi}_{2} \mathrm{O}_{3}$ photocatalyst has a broader absorption spectrum from UV to green light. Therefore, the $\mathrm{Bi}_{2} \mathrm{O}_{3}$ photocatalyst powder has superior decomposition efficiency for organic molecules exposed to white light. As shown in Figure 10, the photocatalytic decomposition efficiency of molecular formaldehyde gas molecules for the fabricated LED was 


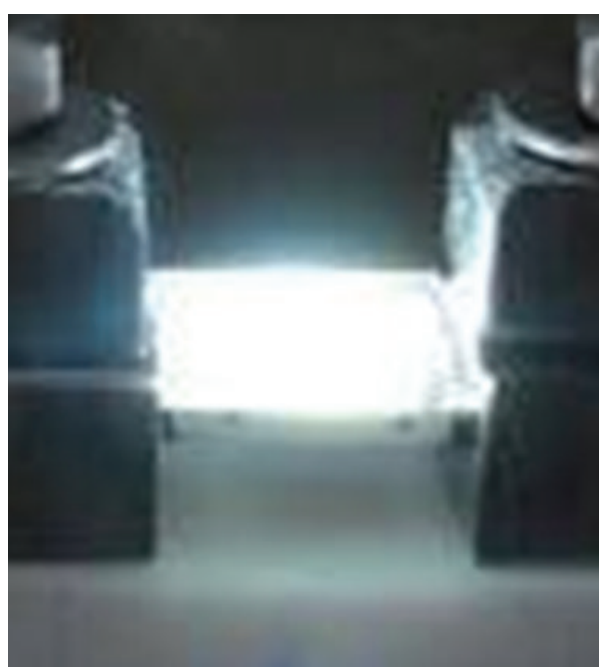

(a)

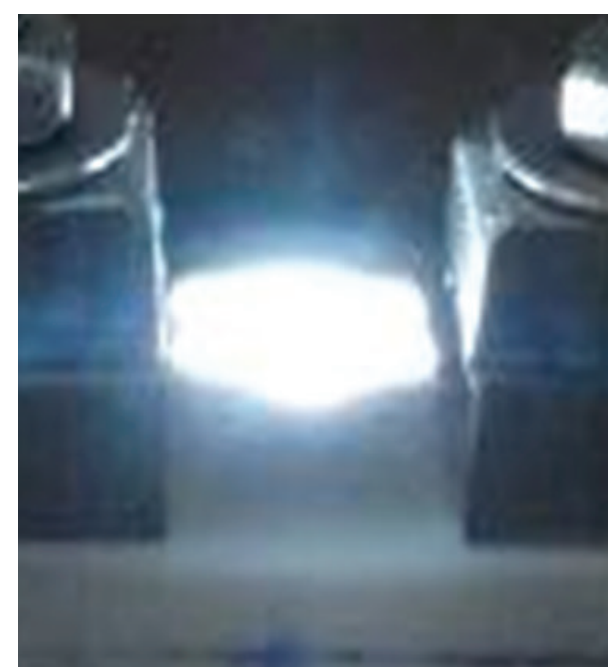

(b)

FIGURE 9: Glare comparison of the LED light source (a) with and (b) without covering a layer of photocatalyst resin.

TABLE 1: The relative intensities and inhibition ability of LED coated with a layer of bismuth oxide photocatalyst at different wavelength.

\begin{tabular}{|c|c|c|c|c|c|}
\hline \multirow{3}{*}{$\begin{array}{l}\text { Category of } \\
\text { photocatalyst }\end{array}$} & \multicolumn{3}{|c|}{ Spectrum region $(\mathrm{nm})$} & \multirow{3}{*}{$\begin{array}{l}\text { Inhibition ability } \\
\text { of UV (\%) }\end{array}$} & \multirow{3}{*}{$\begin{array}{l}\text { Inhibition ability } \\
\text { of visible light (\%) }\end{array}$} \\
\hline & $360-420$ & $420-780$ & $780-1000$ & & \\
\hline & \multicolumn{3}{|c|}{ Power $(\mu \mathrm{W})$} & & \\
\hline Noncoating & 163.7569 & 763.8944 & 8.0054 & NA & NA \\
\hline SP500 & 92.2919 & 544.5116 & 6.5766 & $43.14 \%$ & $26.61 \%$ \\
\hline SP600 & 92.1663 & 560.6209 & 6.9978 & $43.72 \%$ & $28.72 \%$ \\
\hline SP700 & 78.0649 & 511.0019 & 5.8518 & $52.33 \%$ & $33.11 \%$ \\
\hline SP800 & 85.7250 & 536.9019 & 7.5358 & $47.65 \%$ & $29.72 \%$ \\
\hline
\end{tabular}

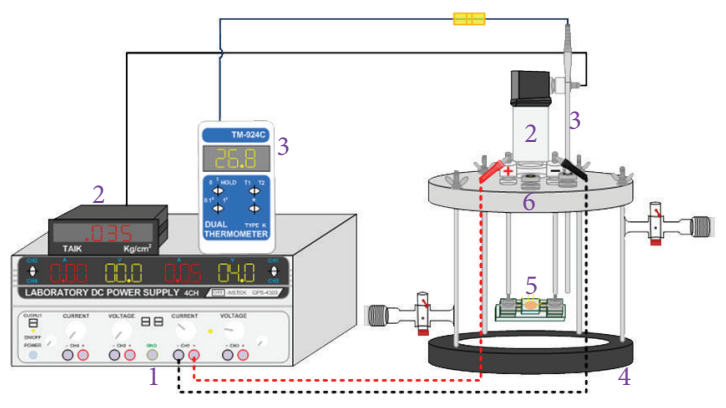

FIGURE 10: Schematic representation of gas-phase organic matter decomposition system.

tested with a specially designed $200 \mathrm{~mL}$ gas-phase organic matter decomposition system. The residual formaldehyde was checked with a gas chromatography flame ionization detector (GC-FID) by sampling with a gas needle. The test result is shown in Figure 11. The molecular formaldehyde gas was decomposed $66.2 \pm 0.60 \mathrm{ppmv}$ in $120 \mathrm{mins}$. The results confirm the practical application of bismuth oxide photocatalysts as a safe and environmentally friendly LED lighting source.

\section{Conclusion}

This study presents a phosphor-based white-light LED with a coating layer of photocatalyst. To show the feasibility of the design, bismuth oxide photocatalysts were synthesized using the spray pyrolysis method at $500^{\circ} \mathrm{C}, 600^{\circ} \mathrm{C}, 700^{\circ} \mathrm{C}$, and $800^{\circ} \mathrm{C}$. Four kinds of bismuth oxide powders were analyzed, and the bismuth oxide powders pyrolyzed at $700^{\circ} \mathrm{C}$ exhibited the most favorable ability to inhibit. The UV-suppressed ratio reached $52.33 \%$ in the region from 360 to $420 \mathrm{~nm}$; the visible light suppression ratio was $33.11 \%$ in the region from 420 to $780 \mathrm{~nm}$. The proposed white-light LEDs were fabricated with CIE chromaticity coordinates $(x, y)$ of $(0.349$, 0.393 ) and correlated color temperature of $4991 \mathrm{~K}$ with a dominant wavelength of $564 \mathrm{~nm}$. The color rendering index reached 90 . The coating layer of photocatalyst can also act as an air purifier and diffuse glare. Thus, the experimental 


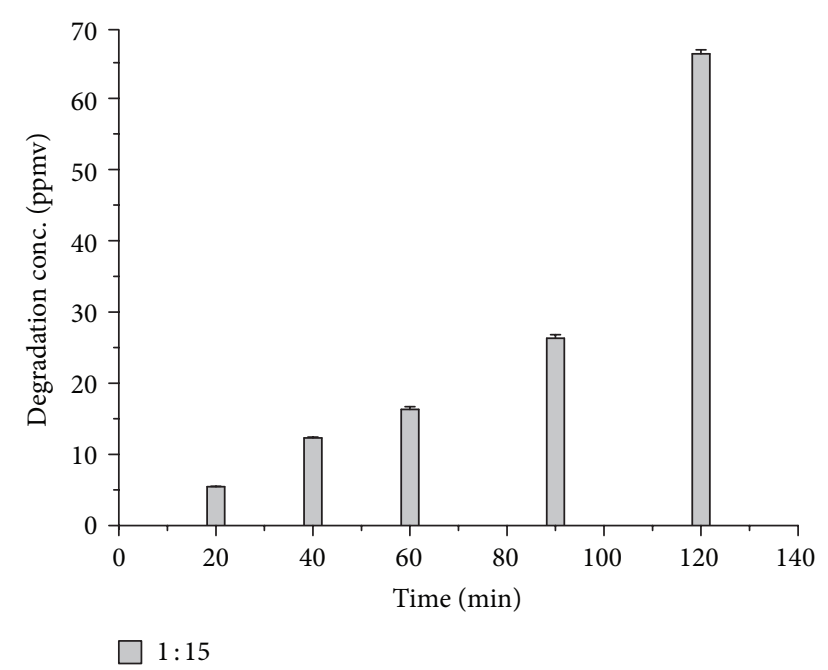

FIgURE 11: The efficiency of bismuth oxide photocatalyst decomposes formaldehyde.

results demonstrated a safe and environmentally friendly LED lighting source.

\section{Acknowledgments}

The authors would like to thank the National Science Council of Taiwan for financially supporting this research under Contract nos. NSC 100-2632-E-035-001-MY3, NSC 101-2221E-035-053 and the NOVA project at Feng Chia University of Taiwan for financially supporting this research.

\section{References}

[1] R. D. Dupuis and M. R. Krames, "History, development, and applications of high-brightness visible light-emitting diodes," Journal of Lightwave Technology, vol. 26, no. 9, pp. 1154-1171, 2008.

[2] R. Mirhosseini, M. F. Schubert, S. Chhajed, J. Cho, J. K. Kim, and E. F. Schubert, "Improved color rendering and luminous efficacy in phosphor-converted white light-emitting diodes by use of dual-blue emitting active regions," Optics Express, vol. 17, no. 13, pp. 10806-10813, 2009.

[3] M. K. Lee, C. L. Ho, and C. H. Fan, "High light extraction efficiency of gallium nitride light emitting diode with silicon oxide hemispherical microlens," Applied Physics Letters, vol. 92, no. 6, Article ID 061103, 2008.

[4] Y. Ohno, "Spectral design considerations for white LED color rendering," Optical Engineering, vol. 44, no. 11, Article ID 111302, 2005.

[5] T. S. Kim, S.-M. Kim, Y. H. Jang, and G. Y. Jung, "Increase of light extraction from GaN based light emitting diodes incorporating patterned structure by colloidal lithography," Applied Physics Letters, vol. 91, no. 17, Article ID 171114, 2007.

[6] Anses Press Kit, Lighting Systems Using Light-Emitting Diodes: Health Issues To Be Considered, 2010.

[7] J.-C. Su, C.-L. Lu, and C.-W. Chu, "Design and fabrication of white light emitting diodes with an omnidirectional reflector," Applied Optics, vol. 48, no. 26, pp. 4942-4946, 2009.
[8] J.-C. Su and C.-L. Lu, "Color temperature tunable white light emitting diodes packaged with an omni-directional reflector," Optics Express, vol. 17, no. 24, pp. 21408-21413, 2009.

[9] C. Shen, H. Feng, Z. Xu, and S. Jin, "GaInN light-emitting diodes with omni-directional reflector using nanoporous $\mathrm{SnO} 2$ film," Chinese Optics Letters, vol. 6, no. 2, pp. 152-153, 2008.

[10] O. Rico-Fuentes, E. Sánchez-Aguilera, C. Velasquez, R. OrtegaAlvarado, J. C. Alonso, and A. Ortiz, "Characterization of spray deposited bismuth oxide thin films and their thermal conversion to bismuth silicate," Thin Solid Films, vol. 478, no. 1-2, pp. 96-102, 2005.

[11] C. Wang, C. Shao, Y. Liu, and L. Zhang, "Photocatalytic properties $\mathrm{BiOCl}$ and $\mathrm{Bi}_{2} \mathrm{O}_{3}$ nanofibers prepared by electrospinning," Scripta Materialia, vol. 59, no. 3, pp. 332-335, 2008.

[12] H. Li, K. Li, and H. Wang, "Hydrothermal synthesis and photocatalytic properties of bismuth molybdate materials," Materials Chemistry and Physics, vol. 116, no. 1, pp. 134-142, 2009.

[13] A. Martínez-de la Cruz and U. M. G. Pérez, "Photocatalytic properties of $\mathrm{BiVO} 4$ prepared by the co-precipitation method: degradation of rhodamine $B$ and possible reaction mechanisms under visible irradiation," Materials Research Bulletin, vol. 45, no. 2, pp. 135-141, 2010.

[14] H. Weidong, Q. Wei, W. Xiaohong, D. Xianbo, C. Long, and J. Zhaohua, "The photocatalytic properties of bismuth oxide films prepared through the sol-gel method," Thin Solid Films, vol. 515, no. 13, pp. 5362-5365, 2007.

[15] Z. Yu, J. Zhang, H. Zhang et al., "Facile solvothermal synthesis of porous $\mathrm{Bi}_{2} \mathrm{O}_{3}$ microsphere and their photocatalytic performance under visible light," Micro and Nano Letters, vol. 7, no. 8, pp. 814-817, 2012.

[16] L. Leontie, M. Caraman, M. Alexe, and C. Harnagea, "Structural and optical characteristics of bismuth oxide thin films," Surface Science, vol. 507-510, pp. 480-485, 2002. 

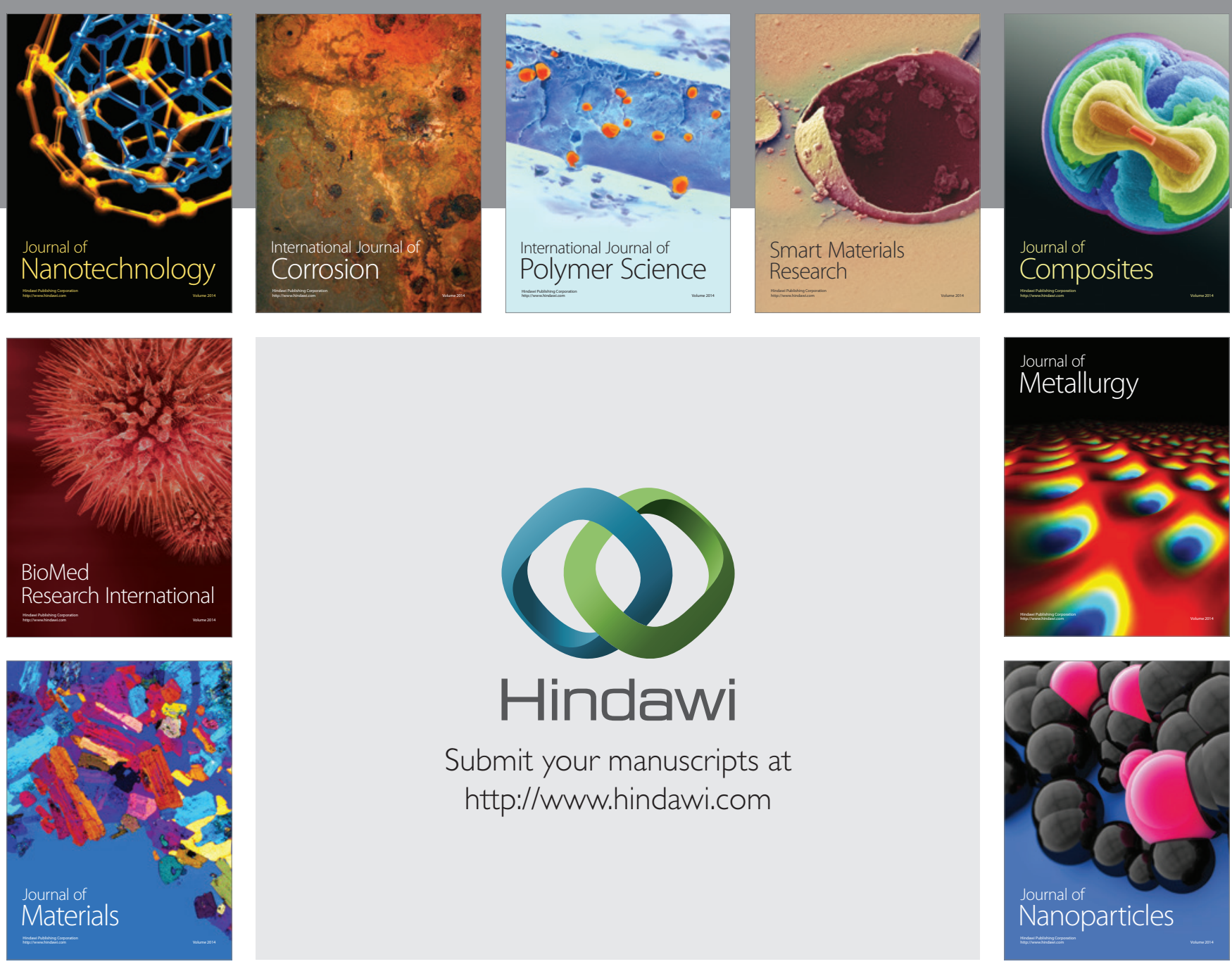

Submit your manuscripts at http://www.hindawi.com
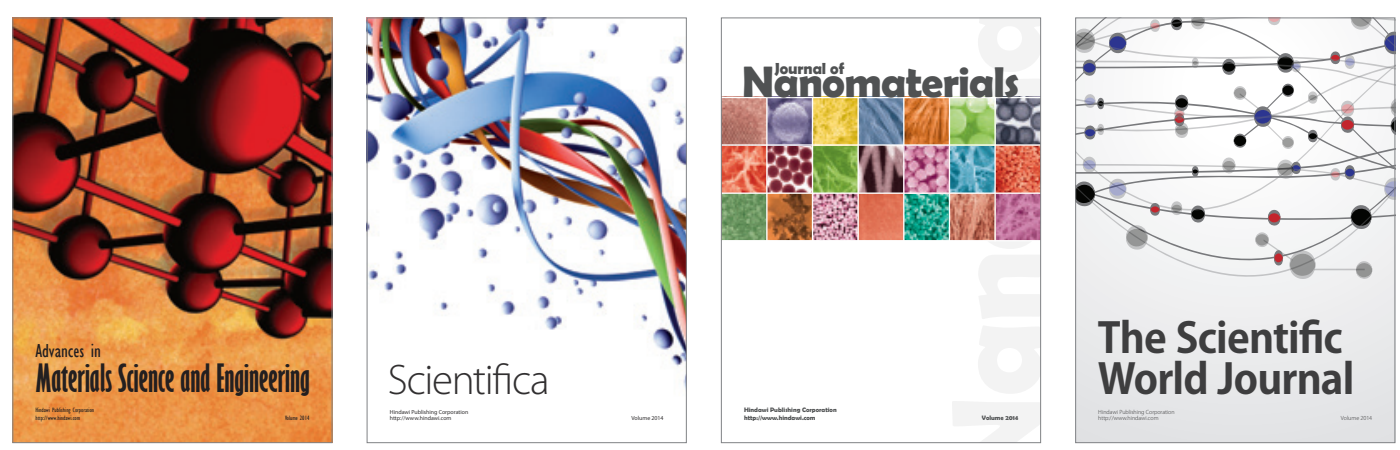

\section{The Scientific World Journal}
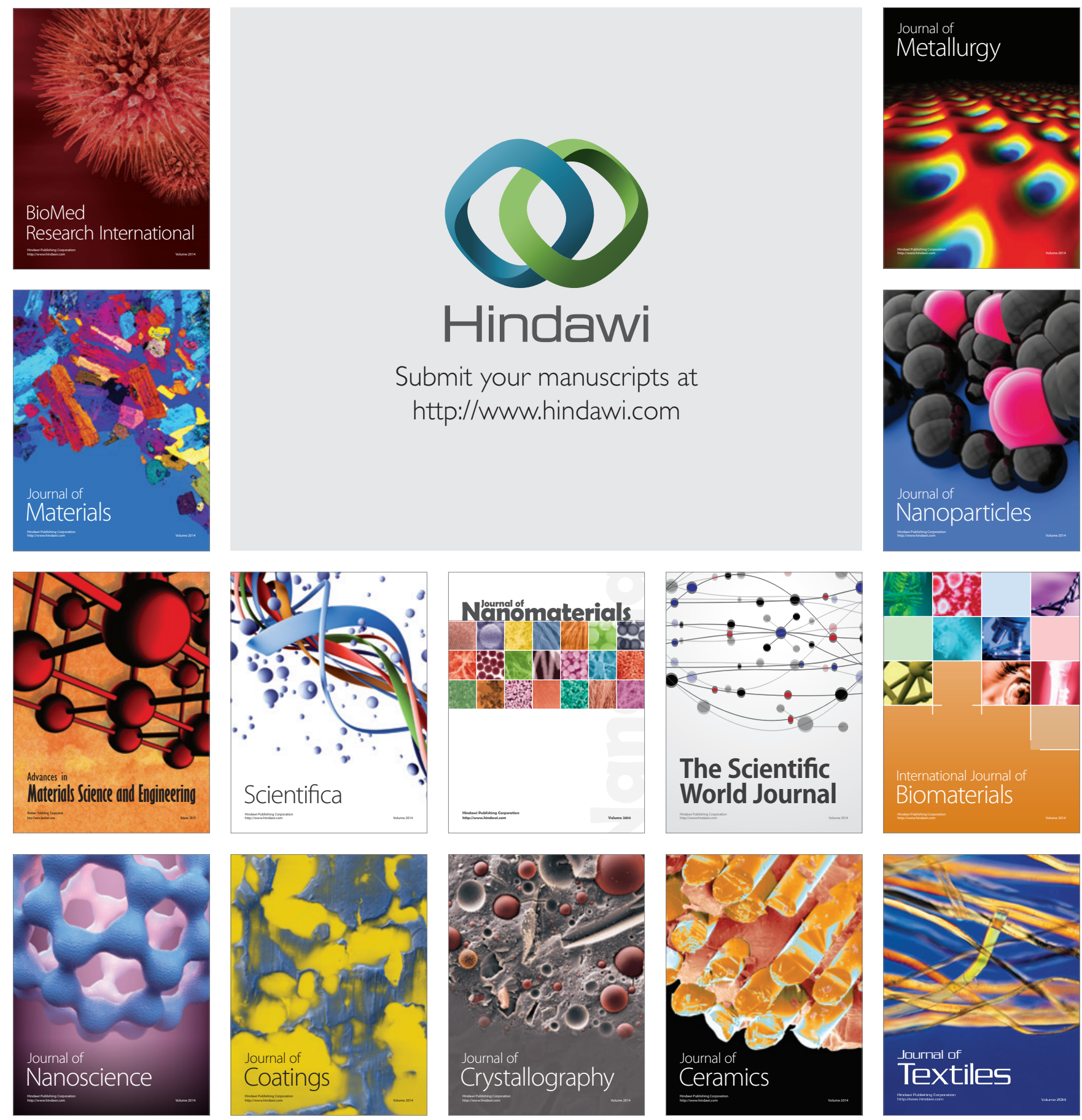